\title{
Downstaging of carcinoma cervix: yet to reach the unreached
}

\author{
Kavita Mahadevappa ${ }^{1}$, Naveen Prasanna ${ }^{1}$, Shobha Bembalgi ${ }^{1}$, \\ Sharanabasav Murugendrayya Choukimath ${ }^{2}$
}

\author{
${ }^{1}$ Department of Obstetrics and Gynecology, Karnataka Institute of Medical Sciences, Hubli 580021, Karnataka, India \\ ${ }^{2}$ Department of Pathology, Karnataka Institute of Medical Sciences, Hubli 580021, Karnataka, India
}

Received: 18 November 2015

Revised: 05 January 2016

Accepted: 08 January 2016

\section{*Correspondence:}

Dr. Kavita Mahadevappa,

E-mail: kavipgi10@gmail.com

Copyright: () the author(s), publisher and licensee Medip Academy. This is an open-access article distributed under the terms of the Creative Commons Attribution Non-Commercial License, which permits unrestricted non-commercial use, distribution, and reproduction in any medium, provided the original work is properly cited.

\section{ABSTRACT}

Background: To know the incidence, presenting symptoms and stages of carcinoma cervix in the patients visiting KIMS, Hubli, Karnataka in the year 2014.

Methods: This is a prospective cross-sectional study from January 2014 to December 2014 in Karnataka Institute of Medical Sciences, Karnataka. All patients attending the gynaecological OPD were included in the study. After taking detailed history, patients underwent general physical examination, per speculum and pelvic examination. Patients were divided into 3 groups based on the per speculum and pelvic examination. Group 1 - only PAP smear was taken in women with normal cervix. Group 2 - PAP smear, visual inspection of cervix with acetic acid and biopsy was taken in women with abnormal cervix. Group 3 - only Cervical biopsy was taken and clinical staging was done in women with a suspicious cervix.

Results: Total of 8053 patients were screened and examined for carcinoma cervix. A total of $14(0.17 \%)$ preinvasive lesions and $85(1.05 \%)$ invasive lesions were detected. Out of 85 invasive lesions, the most common pathology was squamous cell carcinomas in $78(91.76 \%)$ patients, adenocarcinomas in $6(7.05 \%)$ patients and adenosquamous carcinoma in $1(1.17 \%)$ patient. The most common symptoms of carcinoma cervix were WDPV- 48 (56.4\%), Irregular vaginal bleeding- $19(22.3 \%)$, postmenopausal bleeding- $10(11.7 \%)$ and in advanced cases, VVF - $5(0.05 \%)$, RVF$1(0.01 \%)$ and Uraemia - $2(0.02 \%)$. Most of the patients examined were having disease in stage III $-51(60 \%)$ cases, stage IV - $26(30.58 \%)$ cases, stage I $-5(5.8 \%)$ cases and stage II $-3(3.52 \%)$ cases.

Conclusions: Approximately one in every 100 patients examined in OPD, turned out to be a case of carcinoma cervix, out of which more than $90 \%$ patients were diagnosed to be in advanced stage. This huge burden of cases raises the question about screening of carcinoma cervix in rural areas, which needs to be improved. Hence lot has to be done than said, so that screening program of cancer cervix reaches the unreached.

Keywords: Cervical cancer, Downstaging of cancer cervix, PAP smear, Suspicious cervix, Cervical biopsy

\section{INTRODUCTION}

Cervical cancer is the second most common cancer in women worldwide. Approximately $80 \%$ of cancer cervix occurs in developing countries. In India, cervical cancer is the most common cancer among women and it is also the most common cause of cancer deaths. The worldwide incidence of cervical cancer is approximately 510,000 new cases annually, with approximately 288,000 deaths worldwide. ${ }^{1}$ Approximately 132,000 new cases are diagnosed and 74,000 deaths occur annually in India, accounting to nearly $1 / 3^{\text {rd }}$ of the global cervical cancer deaths. $^{2}$ Indian women face a $2.5 \%$ cumulative lifetime risk and $1.4 \%$ cumulative death risk from cervical cancer. It is considered a public health problem and priority in cancer control programmes by WHO. Infection with Human Papilloma virus (HPV) has been identified as a primary aetiological factor in preinvasive disease and 
cervical cancer. At any given time, about $6.6 \%$ of women in the general population are estimated to harbor cervical HPV infection. ${ }^{2}$ Prevention of cervical cancer is by screening, diagnosis and treatment of preinvasive diseases and promoting safe sexual practices, lifestyle modifications and HPV vaccines. Screening by PAP smear has reduced the incidence in developed countries, but implementation of these techniques have not been successful in developing countries. The WHO has introduced down staging for developing countries, by using clinical approaches for detection of the disease, where trained paramedical personnel do a speculum examination and inspect the cervix, identify any visible abnormalities and refer cases with suspicious appearance to centres with facilities for diagnosis and treatment. Our Institute is situated in North Karnataka, which caters to some of the socioeconomically backward districts. Our study is aimed at knowing the burden of the disease, the presenting symptoms and stage of cancer cervix in women attending our hospital, using downstaging technique.

\section{Aims and objectives}

To know the incidence, presenting symptoms and stages of carcinoma cervix in the patients visiting KIMS, Hubli, Karnataka in the year 2014.

\section{METHODS}

This is a prospective cross-sectional study of women detected to have cancer cervix from January 2014 to December 2014 in Karnataka Institute of Medical Sciences, Karnataka. All patients attending the gynaecological OPD were included in the study.

\section{Exclusion criteria}

1. Unmarried,

2. Patients $<21$ years,

3. Previously diagnosed case of carcinoma cervix.

The history included the age, socioeconomic status, and multiple sexual partners, age at menarche, age at marriage, parity index, history of tobacco use, use of OCPs, and previous history of PID treatment. Patients underwent general physical examination, per speculum and pelvic examination. Patients were divided into 3 groups based on the per speculum and pelvic examination as shown in Figure 1. Group 1 - Apparently normal looking cervix. Group 2 - Abnormal cervix (hypertrophy, redness / congestion, irregular surface, distortion, erosion (does not bleed on touch), polyp / growth (with smooth surface). PAP smear, visual inspection of cervix with acetic acid (VIA) and cervical biopsy were taken. Group 3-Suspicious of malignancy (patients having a cauliflower or ulcerative growth on cervix or cervix bleeds on touch. Biopsy was taken and staging was done.

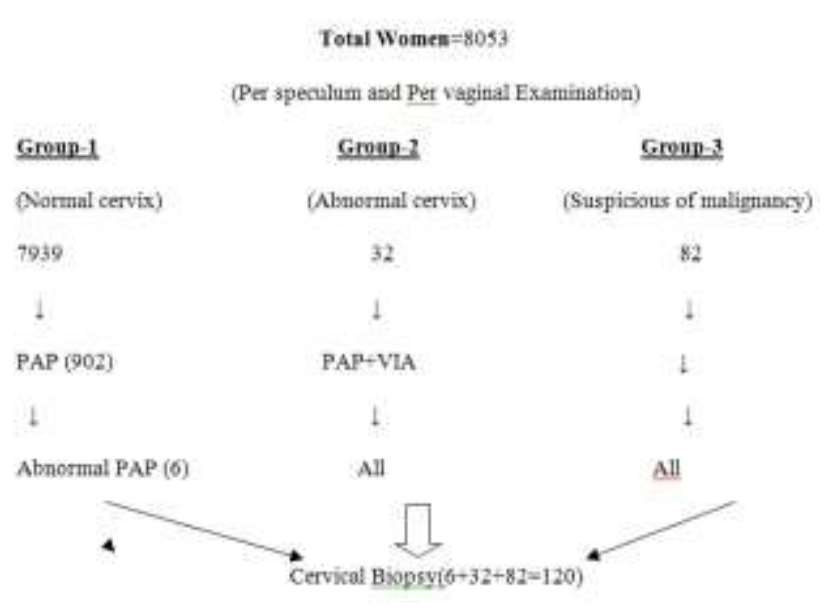

Figure 1: Flow chart.

\section{RESULTS}

Total of 8053 patients were screened and examined for carcinoma cervix. There were 7939 patients in Group 1, in whom PAP smear was taken on OPD basis. Out of which only 902 patients reported in the cytology department for reporting. There were 32 patients in Group 2, who were admitted and subjected for PAP, VIA and cervical biopsy. Table 1, shows PAP reports of 934 patients (902 of Group $1+32$ of Group 2). 635 patients showed inflammatory smear, 9 patients (5 in Group $1+4$ in Group 2) had LSIL. Seven patients showed HSIL all belonged to Group 2. One patient had ASCUS belonged to group 1. Three patients showed squamous cell carcinoma, belonged to Group 2. There were 82 patients in group 3, who were clinically diagnosed as cancer cervix and were admitted for biopsy. Table 2, shows, cervical biopsy report of 120 patients ( 6 from Group 1 with abnormal PAP report + all 32 from Group $2+$ all 82 from Group 3). A total of $17(0.21 \%)$ preinvasive lesions and $85(1.05 \%)$ invasive lesions were detected. Out of 85 invasive lesions, the most common pathology was squamous cell carcinomas in $78(91.76 \%)$ patients, adenocarcinomas in $6(7.05 \%)$ patients and adenosquamous carcinoma in $1(1.17 \%)$ patient. Clinical staging was done in 85 cancer cervix patients. Table 3 , shows the staging of cancer cervix patients. Out of 85 patients, $79(92.94 \%)$ presented in the late stage (IIB to IVB) cancer cervix. All the patients having cancer cervix belonged to lowsocioeconomic status, and 71 patients had sexual exposure before 20years of age and all were multiparous. Out of 85 cases of cancer cervix, 35 cases were seen in age group of 60-70years and least number of cases were seen after 70years of age (Table 4). The most common symptoms of carcinoma cervix were disharge PV- 48 (56.4\%), irregular vaginal bleeding- 19 (22.3\%), postmenopausal bleeding- $10(11.7 \%)$ and in advanced cases, vesicovaginal fistula (VVF) - 5 (0.05\%), rectovaginal fistula $(\mathrm{RVF})-1(0.01 \%)$ and Uraemia -2 $(0.02 \%)$ as shown in Table 5 . 
Table 1: PAP smear reports.

\begin{tabular}{|lll|}
\hline PAP report & Total (934) & $\%$ \\
\hline Normal & 133 & 14.23 \\
\hline Inflammatory & 635 & 67.98 \\
\hline Chronic cervicitis & 146 & 15.63 \\
\hline LSIL & 9 & 0.96 \\
\hline HSIL & 7 & 0.74 \\
\hline ASCUS & 1 & 0.10 \\
\hline Sq. cell carcinoma & 3 & 0.32 \\
\hline
\end{tabular}

Table 2: Histopathology of cervical biopsies.

\begin{tabular}{|ll|}
\hline HPE of cervical biopsy & Cases (120) \\
\hline Chronic cervicitis & 18 \\
\hline Preinvasive lesions & \\
\hline CIN 1---- & 9 \\
\hline CIN 2---- & 5 \\
\hline CIN 3---- & 3 \\
\hline Invasive lesions & \\
\hline Squamous cell Ca & 78 \\
\hline Adenocarcinoma & 6 \\
\hline Adenosquamous & 1 \\
\hline
\end{tabular}

Table 3: Clinical staging of cancer cervix patients.

\begin{tabular}{|ll|l|}
\hline Staging cancer cervix & Total (85) & Percentage \\
\hline Stage IA----- & 2 & $2.35 \%$ \\
\hline Stage IB---- & 3 & $3.52 \%$ \\
\hline Stage IIA----- & 1 & $1.17 \%$ \\
\hline Stage IIB---- & 2 & $2.35 \%$ \\
\hline Stage IIIA---- & 31 & $36.47 \%$ \\
\hline Stage IIIB---- & 20 & $23.52 \%$ \\
\hline Stage IVA--- & 12 & $14.11 \%$ \\
\hline Stage IVB- & 14 & $16.47 \%$ \\
\hline
\end{tabular}

Table 4: Demography of patients with cancer cervix.

\begin{tabular}{|l|l|}
\hline Age group & Cases \\
\hline $30-40$ & 8 \\
\hline $40-50$ & 17 \\
\hline $50-60$ & 22 \\
\hline $60-70$ & 35 \\
\hline$>70$ & 3 \\
\hline Age at marriage & Cases \\
\hline$<20$ & 71 \\
\hline$>20$ & 14 \\
\hline
\end{tabular}

\section{DISCUSSION}

In our study out of 8053 patients, $17(0.21 \%)$ patients had preinvasive lesions and $85(1.05 \%)$ patients had cancer cervix. In a various population, incidence of cancer cervix is represented as age adjusted rate per 100000 females. The incidence of cervical cancer varies widely among countries with world age-standardised rates ranging from $<1$ to $>50$ per 100000 . Cervical cancer is the leading cause of cancer-related death among women in Eastern, Western and Middle Africa; Central America; South-Central Asia and Melanesia. The highest incidence rate is observed in Guinea, with $\sim 6.5 \%$ of women developing cervical cancer before the age of 75 years. India is the country with the highest disease frequency with 134000 cases and 73000 deaths. ${ }^{3}$ The recent NCRP (National Cancer Registry Programme) data show that between 2009 and 2011 Aizawl district in the north eastern part of India had the highest levels of cervical cancer at an age-adjusted rate of 24.3, followed by Barshi expanded at 19.5 and Bangalore at 18.9. ${ }^{4}$ India also has the highest age standardized incidence of cervical cancer in South Asia at 22, compared to 19.2 in Bangladesh, 13 in Sri Lanka, and 2.8 in Iran. ${ }^{5}$

Table 5: Symptoms and signs of cancer cervix patients.

\begin{tabular}{|lll|}
\hline Symptoms & Total & $\%$ \\
\hline Discharge PV & 48 & 56.4 \\
\hline Irregular vaginal bleeding & 19 & 22.3 \\
\hline Postmenopausal bleeding & 10 & 11.7 \\
\hline VVF & 5 & 0.05 \\
\hline RVF & 1 & 0.01 \\
\hline Uraemia & 2 & 0.02 \\
\hline
\end{tabular}

Out of 85 cases of cancer cervix, 35 cases were seen in age group of 60-70years. And least number of cases was seen after $70 y e a r s$ of age. The age distribution worldwide is bimodal, with two peaks one between 35 and 40 years and the second between 55 and 65years. Recent statistics in India reveal that age specific incidence increases from $35 y e a r s$ to reach a peak between 55 and 64years. The mean age at diagnosis is 47 years in west and around the mid-forties in India. According to Sreedevi A et al, the peak age of occurrence of cervical cancer in India is between 55 and 59 years. $^{6}$ In a population-based prospective cohort study in the southern part of India, there was a 2.5 -fold increase in risk among women aged 50-59 years compared to those aged 30-39. There was a higher risk with more children and lack of education. ${ }^{7}$ Similarly, a hospital-based susceptibility study in North India found an increase in cytopathological abnormalities with increasing age and parity. ${ }^{8}$

An analysis of population-based surveys indicates that coverage of cervical cancer screening in developing countries is $19 \%$ compared to $63 \%$ in developed countries and ranges from $1 \%$ in Bangladesh to $73 \%$ in Brazil. ${ }^{9}$ However, older and poor women who are at the highest risk of developing cancer are least likely to undergo screening. India still remains far from making cytology available to masses due to lack of infrastructure and trained personnel. The challenges and failure in implementing cervical cytology screenings in poor settings has resulted into exporing alternate methods for downstaging of cancer cervix, which include visual 
inspection after acetic acid (VIA), visual inspection after acetic acid with magnification (VIAM), visual inspection after lugol's iodine (VILI) and single visit approach. There is a lack of a common protocol for screening in India, which has led to difference in incidence, treatment and survival. Opportunistic screening in various regions of India varied from $6.9 \%$ in Kerala to $0.006 \%$ in the western state of Maharashtra. ${ }^{10,11}$ Randomized trial conducted in Tamil Nadu for the single visit approach reported that follow up after 7 years showed a significant $25 \%$ reduction cervical cancer incidence, a significant $35 \%$ reduction in cervical cancer mortality and a $27 \%$ reduction in the incidence of Stage II or advanced cancer compared to control group. ${ }^{12}$ In our study all the patients underwent physical examination and 7939 had normal looking cervix in whom PAP smear was taken, but however even in a tertiary institute like ours, only 902 patients payed for this investigation and came with the PAP report. If this PAP smear investigation was done without charge and entirely be the responsibility of the institute to submit the smear and collect the report, we could have achieved a $100 \%$ opportunistic screening in these patients. However mere physical examination has helped to detect the high risk patients having suspicious cervix and all of them were admitted so that none of them were lost to follow up, so that necessary treatment could be given. If the physical examination can be done at rural level by the paramedical personnel and those showing suspicious or abnormal cervix are referred to higher institute, then the burden of cancer cervix can be reduced to a large extent.

The women in our study presented with the following symptoms of discharge per vagina (56.4\%), irregular vaginal bleeding $(22.3 \%)$, postmenopausal bleeding (11.7\%), VVF (0.05\%), RVF $(0.01 \%)$ and Uraemia $(0.02 \%)$. Haemorrhage is the most important symptom of early stage of cancer cervix, where patient may present with postcoital bleeding and takes the form of irregular vaginal bleeding, with a trickle of blood which may persists for several days. Other symptoms develop in late stages, by then the diagnosis becomes obvious. Out of 85 cases of cancer cervix in our study, 79 (92.94\%) presented with late stage (IIB to IVB) cancer cervix. According to Dutta $S$ et al most of the cases $(85 \%)$ presented in advanced and late stages, and more than half $(63 \%-89 \%)$ have regional disease at the time of presentation. ${ }^{13}$ Cervical cancer diagnosis and treatment in the advanced stages makes it a costly exercise, with a poor prognosis resulting in poor compliance. Five-year survival rates in Mumbai population-based cancer registry in 1992-1994 were $47.7 \%$ for cervical cancer. Survival was determined by age and the extent of disease, with younger women having longer survival. ${ }^{14}$ In the 1980s the Bangalore registry reported a 5-year survival of $34.4 \%$ and relative survival of $38.3 \%$. This registry also observed a significant decline in the proportion of patients presenting in Stage IV from 1982 to 1989 , indicating a probable improvement in awareness levels. ${ }^{15}$ The most common histopathological type of cancer cervix in our study was squamous cell carcinoma (78), adenosquamous carcinoma (1) and adenocarcinoma (6). According to literature predominant type is squamous cell carcinoma comprising 80 to $85 \%$ of cervical cancers arising from ectocervical epithelium. Adenocarcinomas constitute 15 to $20 \%$ arising from the columnar epithelium of the endocervix. According to Satija A, the common histological type found in the ectocervix is squamous cell carcinoma and that in the endocervix is adenocarcinoma. $^{16}$

According to National Cancer Registry Programme there has been a decline in the incidence of cancer cervix as seen across all registries including the rural registry at Barshi. In the Bangalore registry, the age-adjusted rate fell from 32.4 in 1982 to 18.7 in 2009, in Barshi from 22.1 in 1988 to 14.1 in 2010, in Chennai from 41 to 16.7 in 2009, and in Thiruvananthapuram from 9.2 in 2005 to 7.7 in $2011 .^{4}$ The annual percentage decrease ranged from a minimum of $1.3 \%$ in Bhopal to $3.5 \%$ in Chennai in the years from 1982 to $2010 .{ }^{17}$ Among hospital-based registries, over a 30-year study period in the Mumbai registry there was an estimated annual percent change in cervical cancer by $-1.8 \%$ (95\% CI: $-2.0,-1.6)$, which was associated with a significant increase in breast cancer. ${ }^{18}$ Cervical cancer rates among women in the 30 64 age group decreased by $1.8 \%$ per year on average but still accounted for $16 \%$ of the total female cancer burden. ${ }^{18}$ Chhabra et al found an increase in cervical cancer among outpatients from $0.55 \%$ in 1983 to $3.5 \%$ in 2007. ${ }^{19}$ But over the years from $1983-1987$ to $2003-2007$ there was a fall in the percentage of all cervical cancers from $43.8 \%$ to $37.6 \%$. On the other hand, in Odisha, cancer cervix was the second most common cancer, with an increase of $3.1 \%$ from 2001 to $2011 .^{20}$ Cervical cancer constitute $13 \%$ of all cancers globally. The disease is preventable by screening, early diagnosis and treatment. We have come a long way from PAP smear to HPV DNA examination for screening of the disease. International data shows a marked decline in incidence of cancer cervix in developed countries with successive screening programs and early interventions. India also has shown a decline in the disease in the past decade. The exact incidence will be difficult to obtain, because of under reporting in rural areas. Cervical cancer is the disease of low socioeconomic population. A meta-analysis of social inequality and the risk of cervical cancer showed a $100 \%$ increased risk in the low-social-class categories for the development of invasive cervical cancer. Although this difference was observed in all countries, it was stronger in low- and middle-income countries. ${ }^{21}$ All our patients who were diagnosed with cancer cervix belonged to the lower socioeconomic status. Health education is a prerequisite of any screening programme. Adequate programmes of public and professional education to make them aware of the symptoms and signs of the disease and of its potential curability if detected early should be organised to accompany, and preferably precede, introduction of the screening programme. 


\section{CONCLUSIONS}

Approximately one in every 100 patients examined in our hospital, turned out to be a case of carcinoma cervix, out of which more than $90 \%$ patients were diagnosed to be in advanced stage. This huge burden of cases raises the question about screening of carcinoma cervix in rural areas, which needs to be improved. Hence lot has to be done than said, so that screening program of cancer cervix reaches the unreached.

Funding: No funding sources Conflict of interest: None declared

Ethical approval: The study was approved by the Institutional Ethics Committee

\section{REFERENCES}

1. Sankaranarayanan R, Ferlay J. Worldwide burden of gynecological cancer: The size of the problem. Best Pract Res Clin Obstet Gynaecol. 2006;20:207-25.

2. WHO/ICO Information Centre on HPV and Cervical Cancer (HPV Information Centre). Summary report on HPV and cervical cancer statistics in India. 2007. Available from:http://www.who.int/hpvcentre. Last Assessed on 2008 May 1.

3. Arbyn M, Castellsague X, DeSanjose S. Worldwide burden of cervical cancer. Ann Oncol. 2011;22:267586.

4. National Centre for Disease Informatics Research, National Cancer Registry Programme, ICMR Three Year Report of Population Based Registries, 20092011 Bangalore, India: NCDIR-NCRP (ICMR;). 2014

5. ICO Information Centre on HPV and cancer. Human Papillomavirus and Related Diseases in India. 2014.

6. Sreedevi A, Javed R, Dinesh A. Epidemiology of cervical cancer with special focus on India. Int $\mathrm{J}$ Womens Health. 2015;7:405-14.

7. Jissa VT, Nea M, Matti H. Sociodemograhic and reproductive risk factors for cervical cancer-a large prospective cohort study from Rural India. Asian Pac J Cancer Prev. 2012;13:2991-5.

8. Misra JS, Srivastava S, Singh U. Risk-factors and strategies for control of carcinoma cervix in India: hospital based cytological screening experience of 35 years. Indian J Cancer. 2009;46(2):155-9.

9. Gakidou E, Stella N, Ziad O. Coverage of cervical cancer screening in 57 countries: low average levels and large inequalities. PloS Med. 2009;5:e132.
10. Aswathy S, Quereshi MA, Kurian B, Leelamoni K. Cervical cancer screening: current knowledge and practice among women in a rural population of Kerala, India. Indian J Med Res. 2012;136(2):20510.

11. Sankaranarayanan R, Nene BM, Shastri SS. HPV screening for cervical cancer in rural India. N Engl J Med. 2009;360:1385-94.

12. Sankaranarayanan R, Esmy PO, Ramkumar R. Effect of visual screening on cervical cancer incidence and mortality in Tamil Nadu: a cluster-randomised trial. Lancet. 2007;370:398-406.

13. Dutta S, Biswas N, Mukheriee G. Evaluation of sociodemographic factors for non compliance to treatment in locally advanced cases of cancer cervix in a rural medical college hospital in India. Indian J of Palliat Care. 2013;19(3):158-65.

14. Yeole BB, Kumar AV, Kurkureet A, Sunny L. Population-based survival from cancers of breast, cervix and ovary in women in Mumbai. Asian Pac J Cancer Prev. 2004;5:308-15.

15. Nandakumar A, Ramnath T, Chaturvedi M. The magnitude of cancer cervix in India. Indian $\mathrm{J}$ Med Res. 2009;130(3):219-21.

16. Satija A. Cervical cancer in India. South Asia centre for chronic disease. [Accessed February16, 2014]. Available from: http://sancd.org/uploads/pdf/ cervical_cancer.pdf.

17. National Centre for Disease Informatics Research, National Cancer Registry Programme, ICMR Time Trends in Cancer Incidence Rates, 1982-2010 Bangalore, India: NCDIR-NCRP (ICMR;). 2013.

18. Dhillon PK, Yeole BB, Dikshit R. Trends in breast, ovarian and cervical cancer incidence in Mumbai, India over a 30-year period, 1976-2005: an ageperiod-cohort analysis. $\mathrm{Br} \mathrm{J}$ Cancer. 2011;105(5):723-30.

19. Chhabra S, Bhavani M, Mahajan N. Cervical cancer in Indian rural women: trends over two decades. J Obstet Gynaecol. 2010;30(7):725-8.

20. Hussain MA, Pati S, Swain S. Pattern and trends of cancer in Odisha, India: a retrospective study.Asian Pac J Cancer Prev. 2012;13(12):6333-6.

21. Seema P, Paul B, Boffetta P. Meta analysis of social inequality and the risk of cervical cancer. Int $\mathbf{J}$ Cancer. 2003;105:687-91.

Cite this article as: Mahadevappa K, Prasanna N, Bembalgi S, Choukimath SM. Downstaging of carcinoma cervix: Yet to reach the unreached. Int J Reprod Contracept Obstet Gynecol 2016;5:349-53. 